Received: 15.06 .2021

Revised: 15.08 .2021

Accepted: 27.08 .2021

DOI: $10.17804 / 2410-9908.2021 .4 .015-022$

\title{
ELEMENTAL COMPOSITION OF CALCIUM PHOSPHATE COATINGS MODIFIED WITH Fe-Cu NANOPARTICLES
}

\author{
V. V. Chebodaeva ${ }^{\text {a)* }}$, M. B. Sedelnikova ${ }^{\text {b) }}$, O. V. Bakina ${ }^{\text {c) }}$, and Yu. P. Sharkeev ${ }^{\text {d) }}$ \\ Institute of Strength Physics and Materials Science, Siberian Branch of the Russian Academy of Sciences, \\ 2/4 Akademicheskii Ave., Tomsk, 634055, Russian Federation \\ a) (iD http://orcid.org/ 0000-0002-1980-3941 vtina5@mail.ru; \\ b) (iD http://orcid.org/0000-0002-5741-6053 smasha5 @yandex.ru; \\ c) iD http://orcid.org/0000-0002-8650-6939 ovbakina@ispms.tsc.ru; \\ d) iD http://orcid.org/0000-0001-5037-245X $\otimes$ sharkeev@ispms.tsc.ru \\ *Corresponding author. E-mail: vtina5@mail.ru \\ Address for correspondence: Academicheskii pr., 8/3, Tomsk, 634021, Russian Federation \\ Tel.: +7 (382) 2866911
}

The object of research is calcium-phosphate coatings doped with $\mathrm{Fe}-\mathrm{Cu}$ nanoparticles. The elemental composition of the calcium-phosphate $(\mathrm{CaP})$ coatings deposited by the microarc oxidation (MAO) method at a voltage of $250 \mathrm{~V}$ is studied. The quantitative content and distribution of $\mathrm{Ca}, \mathrm{P}, \mathrm{O}, \mathrm{Ti}, \mathrm{Fe}$, and $\mathrm{Cu}$ over the coating surface prove to depend on the introduced additional electrolyte components. After modification with $\mathrm{Fe}-\mathrm{Cu}$ nanoparticles, the $\mathrm{Ca}$ content increases from 4.5 at. \% to 6.7 at. \%. The amount of $\mathrm{P}$ and $\mathrm{Ti}$ after the introduction of nanoparticles increases from 11.7 to 22.3 at. $\%$ and from 7.9 to 15.8 at. \%. Oxygen concentration, on the contrary, decreases from 75.9 to 55.0 at. $\%$.

Keywords: calcium-phosphate coatings, hydroxyapatite, $\mathrm{Fe}-\mathrm{Cu}$ nanocomposite particles, nanoparticles, microarc oxidation.

\section{Acknowledgment}

We are thankful to Dr. M.V. Chaikina, leading researcher at the laboratory of intercalation and mechanochemical reactions of the ISSCM SB RAS, for the preparation of stoichiometric hydroxyapatite and to Mr. A. I. Tolmachev, chief exert at the laboratory of nanostructural biocomposites of the ISPMS SB RAS for his assistance in the preparation of titanium plates.

The work was performed within the state assignment to the ISPMS SB RAS, project FWRW2021-0007.

\section{References}

1. Sharkeev Y.P., Psakhie S.G., Legostaeva E.V., Knyazeva A.G., Smolin A.Y., Eroshenko A.Y., Konovalenko I.S., Nazarenko N.N., Belyavskaya O.A., Kulyashova K.S., Komarova E.G., Tolkacheva T.V., Khlusov I.A., Zaitsev K.V., Khlusova M.Y., Polenichkin V.K., Sergienko V.I., Gnedenkov S.V., Sinebryukhov S.L., Puz' A.V., Khrisanfova O.A., Egorkin V.S., Zavidnaya A.G., Terleeva O.P., Mironov I.V., Slonova A.I., Lyamina G.V., Fortuna S.V., Yakovlev V.I., Kulakov A.A., Gvetadze R.S., Khamraev T.K., Abramian S.V. Biokompozity na osnove kaltsiyfosfatnykh pokrytiy, nanostrukturnykh i ultramelkozernistykh bioinertnykh metallov, ikh biosovmestimost i biodegradatsiya [Biocomposites based on calcium-phosphate coatings, nanostructured and ultrafine- 
grained bioinert metals, their biocompatibility and biodegradation]. Tomsk, Izdatelskiy Dom Tomskogo Gosudarstvennogo Universiteta Publ., 2014, 596 p. (In Russian).

2. $\quad$ Li J., Qin L., Yang K., Ma Z., Wang Y., Cheng L., Zhao D. Materials evolution of bone plates for internal fixation of bone fractures: A review. Journal of Materials Science \& Technology, 2020, vol. 36, pp. 190-208. DOI: 10.1016/j.jmst.2019.07.024.

3. Mourico V., Cattalini J.P, Roether J.A, Dubey P., Roy I., Boccaccini A.R. Composite polymer-bioceramic scaffolds with drug delivery capability for bone tissue engineering. Expert Opinion on Drug Delivery, 2013, vol. 10 (10), pp. 1353-1365. DOI: 10.1517/17425247.2013.808183.

4. Sedelnikova M.B., Ugodchikova A.V., Uvarkin P.V., Chebodaeva V.V., Tolkacheva T.V., Schmidt D., Sharkeyev Yu.P. Structural, morphological and adhesive properties of calcium phosphate coatings formed on magnesium alloy by micro-arc oxidation method in electrolyte containing dispersed particles. Russian Physics Journal, 2021. DOI: 10.1007/s11182-021-02398-Z.

5. Sedelnikova M.B., Ugodchikova A.V., Tolkacheva T.V., Chebodaeva V.V., Cluklhov I.A., Khimich M.A., Bakina O.V., Lerner M.I., Egorkin V.S., Schmidt J., Sharkeev Y.P. Surface modification of $\mathrm{Mg} 0.8 \mathrm{Ca}$ alloy via wollastonite micro-arc coatings: Significant improvement in corrosion resistance. Metals, 2021, vol. 11 (5), 754. DOI: 10.3390/met11050754.

6. Karbowniczek J., Muhaffel F., Cempura G., Cimenoglu H., Czyrska-Filemonowicz A. Influence of electrolyte composition on microstructure, adhesion and bioactivity of micro-arc oxidation coatings produced on biomedical Ti6Al7Nb alloy. Surface and Coatings Technology, 2017, vol. 321, pp. 97-107. DOI: 10.1016/j.surfcoat.2017.04.031.

7. Simchen F., Sieber M., Kopp A., Lampke T. Introduction to plasma electrolytic oxidation-an overview of the process and applications. Coatings, 2020, vol. 628 (10). DOI: 10.3390/coatings10070628. 8. Dorozhkin S.V. Calcium orthophosphate deposits: Preparation, properties and biomedical applications. Materials Science and Engineering C, 2015, vol. 55, pp. 272-326. DOI: 10.1016/j.msec.2015.05.033.

9. Khan R.H.U., Yerokhin A.L., Li X., Dong H., Matthews A. Influence of current density and electrolyte concentration on DC PEO titania coatings. Surface Engineering, 2014, vol. 30 (2), pp. 102-108. DOI: 10.1179/1743294413Y.0000000225.

10. Chebodaeva V.V., Nazarenko N.N., Sedelnikova M.B., Gnedenkov S.V., Egorkin V.S., Sinebryukhov S.L., and Sharkeev Yu.P. Effect of Boehmite Nanoparticles on the Structural, Corrosion, and Diffusion Properties of Micro-arc Biocoatings. Inorganic Materials: Applied Research, 2021, vol. 12, No. 3, pp. 691-699. DOI: 10.1134/S2075113321030072.

11. Chebodaeva V., Sedelnikova M., Bazhanova V., Lerner M., Pervikov A., Sharkeev Yu. Influence of Metal Based Nanoparticles on Properties of Micro-arc Calcium Phosphate Coatings. AIP Conference Proceedings, 2019, vol. 2167, pp. 020049-1-020049-4. DOI: 10.1063/1.5131916.

12. Lozhkomoev A.S., Pervikov A.V., Chumaevsky A.V., Dvilis E.S., Paygin V.D., Khasanov O.L., Lerner M.I. Fabrication of $\mathrm{Fe}-\mathrm{Cu}$ composites from electroexplosive bimetallic nanoparticles by spark plasma sintering. Vacuum, 2019, vol. 170, pp. 108980. DOI: 10.1016/j.vacuum.2019.108980.

13. Mueller P.P., May T., Perz A., Hauser H., Peuster M. Control of smooth muscle cell proliferation by ferrous iron. Biomaterials, 2006, 27, pp. 2193-2200. DOI: 10.1016/j.biomaterials.2005.10.042.

14. Lozhkomoev A.S., Pervikov A.V., Chumaevsky A.V., Dvilis E.S., Paygin V.D., Khasanov O.L., Lerner M.I. Fabrication of $\mathrm{Fe}-\mathrm{Cu}$ composites from electroexplosive bimetallic nanoparticles by spark plasma sintering. Vacuum, 2019, vol. 170, pp. 108980. DOI: 10.1016/j.vacuum.2019.108980. 
Подана в журнал: 15.06.2021

УДК 621.794.61

DOI: $10.17804 / 2410-9908.2021 .4 .015-022$

\title{
ЭЛЕМЕНТНЫЙ СОСТАВ КАЛЬЦИЙ-ФОСФАТНЫХ ПОКРЫТИЙ МОДИФИЦИРОВАННЫХ НАНОЧАСТИЦАМИ Fe-Cu
}

\author{
В. В. Чебодаева ${ }^{\text {a)* }}$, М. Б. Седельникова ${ }^{\text {б) }}$, О. В. Бакина ${ }^{\text {в) }}$ Ю. П. Шаркеев ${ }^{\text {r) }}$
}

Институт физики прочности и материаловедения (ИФПМ) СО РАН, д. 8/3, пр. Академический, 634021, г. Томск, Российская Федерация

a) iD http://orcid.org/ 0000-0002-1980-3941 vtina5 @ mail.ru;

б) (iD http://orcid.org/0000-0002-5741-6053 smasha5 @ yandex.ru;

в) iD http://orcid.org/0000-0002-8650-6939 ovbakina@ispms.tsc.ru;

г) iD http://orcid.org/0000-0001-5037-245X $ه$ sharkeev@ispms.tsc.ru

*Ответственный автор. Электронная почта: vtina5@ mail.ru

Адрес для переписки: пр. Академический, д. 8/3, г. Томск, 634021, Российская Федерация Тел.: +7 (382) 286-69-11

Объект исследования - кальций-фосфатные покрытия с введенными в их состав наночастицами $\mathrm{Fe}-\mathrm{Cu}$. Проведено исследование элементного состава и распределения элементов кальций-фосфатных (КФ) покрытий, нанесенных методом микродугового окисления (МДО). Установлено, что количественное содержание и распределение элементов $\mathrm{Ca}, \mathrm{P}, \mathrm{O}, \mathrm{Ti}, \mathrm{Fe}$ и $\mathrm{Cu}$ в поверхностном слое покрытия существенно зависит от введенных дополнительных компонентов электролита. После модификации наночастицами $\mathrm{Fe}-\mathrm{Cu}$ содержание Са увеличивается от 4,5 до 6,7 ат. \%, а количество Р и Ті увеличивается от 11,7 до 22,3 ат. \% и от 7,9 до 15,8 ат. \% соответственно. При этом концентрация кислорода уменьшается от 75,9 до 55,0 ат. \%. Показано, что такое поведение элементов в покрытии определяется участием ионов металлов $\mathrm{Fe}^{3+}$ и $\mathrm{Cu}^{2+}$ во время осаждения покрытия, способствующих интенсификации процессов МДО.

Ключевые слова: кальций-фосфатные покрытия, гидроксиапатит, нанокомпозитные частицы $\mathrm{Fe}-\mathrm{Cu}$, наночастицы, микродуговое оксидирование.

\section{1. Введение}

В настоящее время модификация поверхности биоматериалов для придания им новых физико-химических свойств является перспективным направлением в материаловедении [1-3]. Наиболее важными при взаимодействии биоматериала с биологическими тканями являются свойства его поверхности. Для придания биоактивных свойств металлическим имплантатам из биоинертных сплавов часто наносят на их поверхность кальций-фосфатные (КФ) покрытия $[4,5]$. Для формирования таких покрытий перспективным является метод микродугового оксидирования (МДО), позволяющий наносить на поверхность биоинертных металлов и сплавов покрытия с необходимыми пористостью, химическим и фазовым составами [4-9]. Структура полученных покрытий с открытыми порами позволяет вводить в их состав модифицирующие добавки для улучшения антибактериальных и биоактивных свойств.

Введение дополнительных компонентов в состав покрытий, таких как наночастицы оксигидроксида алюминия $\mathrm{AlO}(\mathrm{OH})$ или оксида цинка $\mathrm{ZnO}$, способствует улучшению функциональных свойств модифицируемых материалов [10-12]. Применение наночастиц $\mathrm{Fe}-\mathrm{Cu}$ с ограниченной смешиваемостью для модификации КФ-покрытия будет способствовать повышению биомеханических, антибактериальных и биоактивных и свойств покрытий $[13,4]$. Такой недостаток покрытий, как их низкая адгезия к титановой подложке, может быть 
устранен путем добавления в состав электролита Fe для улучшения прочностных и адгезионных свойств покрытия. В то же время введение в покрытие $\mathrm{Cu}$ в составе наночастиц $\mathrm{Fe}-\mathrm{Cu}$ будет улучшать его антибактериальные свойства. Известно, что ионы железа и меди являются важным составляющим группы ферментов, катализирующих различные физиологические процессы, таких как связывание кислорода, синтез ДНК и перенос электронов в дыхательной цепи $[13,14]$.

Цель работы - исследование элементного состава микродуговых кальций-фосфатных покрытий, модифицированных наночастицами $\mathrm{Fe}-\mathrm{Cu}$.

\section{2. Материал и методика}

В качестве экспериментальных образцов использовали пластинки с размерами $10 \times 10 \times 1$ мм $^{3}$ из титана марки ВТ1-0. Образцы обрабатывали шлифовальной бумагой с последовательным уменьшением зернистости (Р180, Р400, Р600) на шлифовально-полировальном станке Tegra System (Struers, Denmark, ЦКП «Нанотех» ИФПМ СО РАН) при скорости вращения диска 300 об./мин. Последний этап заключался в очистке от загрязнений с применением ультразвукового воздействия (ультразвуковая мойка Elmasonic 515H), в дистиллированной воде (10 мин) на первом этапе, а затем в этиловом спирте (10 мин).

КФ-покрытие наносили на поверхность титановой подложки методом МДО на установке «MicroArc-3.0» (Лаборатория физики наноструктурных биокомпозитов ИФПМ СО PAН) в анодном потенциостатическом режиме в электролите, в состав которого входили водный 30 \%-й раствор ортофосфорной кислоты $\mathrm{H}_{3} \mathrm{PO}_{4}$, карбонат кальция $\mathrm{CaCO}_{3}$, гидроксиапатит $\mathrm{Ca}_{10}\left(\mathrm{PO}_{4}\right)_{6}(\mathrm{OH})_{2}$ и нанокомпозитный порошок $\mathrm{Fe}-\mathrm{Cu}$ [3]. Нанокомпозитный порошок $\mathrm{Fe}-\mathrm{Cu}$ с соотношением $\mathrm{Fe} / \mathrm{Cu}$, равным 46/54 мас. \% был получен методом совместного электрического взрыва проволочек железа и меди [13]. Для формирования покрытий методом МДО использовали следующие параметры: длительность импульса - 100 мкс; частота следования импульсов - 50 Гц; величина импульсного напряжения - 250 В; длительность процесса 10 мин. Порошок ГА стехиометрического состава был получен методом механохимического синтеза (МХС) в Институте химии твердого тела и механохимии СО РАН (ИХТТМ СО РАН, г. Новосибирск).

Морфологию и элементный состав КФ-покрытий исследовали методом растровой электронной микроскопии (PЭМ) на микроскопе «LEO EVO-50» с приставкой «INCA-350» для энергодисперсионного микроанализа (ЦКП ИФПМ СО РАН «Нанотех», г. Томск).

\section{3. Результаты и их обсуждение}

На рис. 1 представлены результаты исследования поверхности КФ-покрытий методом РЭМ. Результаты проведенного исследования показали, что КФ-покрытия обладают развитой поверхностью и представлены сферическими структурными элементами с порами (рис. $1 a$ ). Также на поверхности покрытий присутствуют поры, локализованные в углублениях между сфероидальными элементами. Исследования покрытий с помощью энергодисперсионного микроанализа показали, что в состав таких покрытий входят кальций (4,5 ат. \%), фосфор $(11,7$ ат. \%), кислород (75,9 ат. \%) и титан (7,9 ат. \%).

Введение в электролит нанокомпозитных частиц $\mathrm{Fe}-\mathrm{Cu}$ способствует усилению интенсивности плазмохимических реакций в процессе нанесения МДО-покрытий и образованию на их поверхности разрушенных сферических образований и осколков. Поверхность КФ-покрытий, нанесенных на титановую подложку в электролите с наночастицами $\mathrm{Fe}-\mathrm{Cu}$, также представлена сферическими элементами и порами (рис. 1 б). Добавление нанокомпозитных частиц $\mathrm{Fe}-\mathrm{Cu}$ в электролит приводит к формированию на поверхности сферических структурных элементов и между ними осколков со средним размером 1 мкм (рис. 16 , выделены красными эллипсами). 


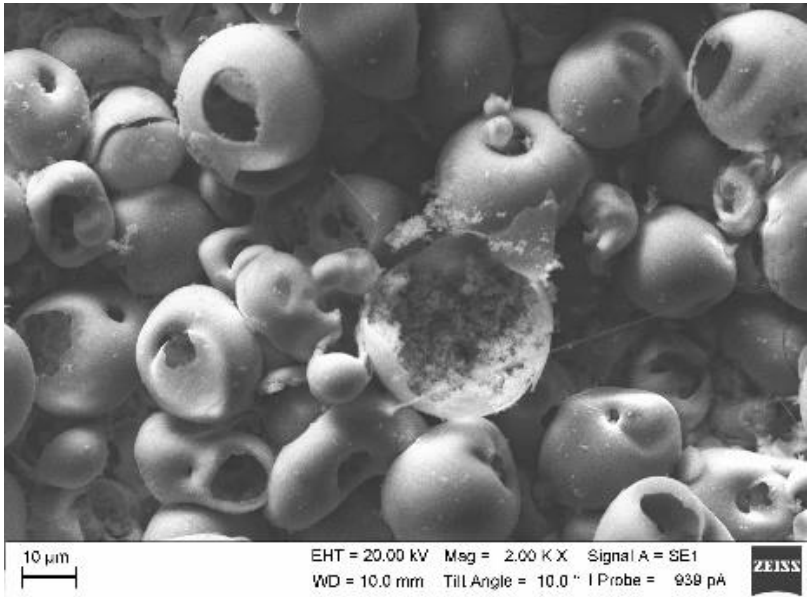

$a$

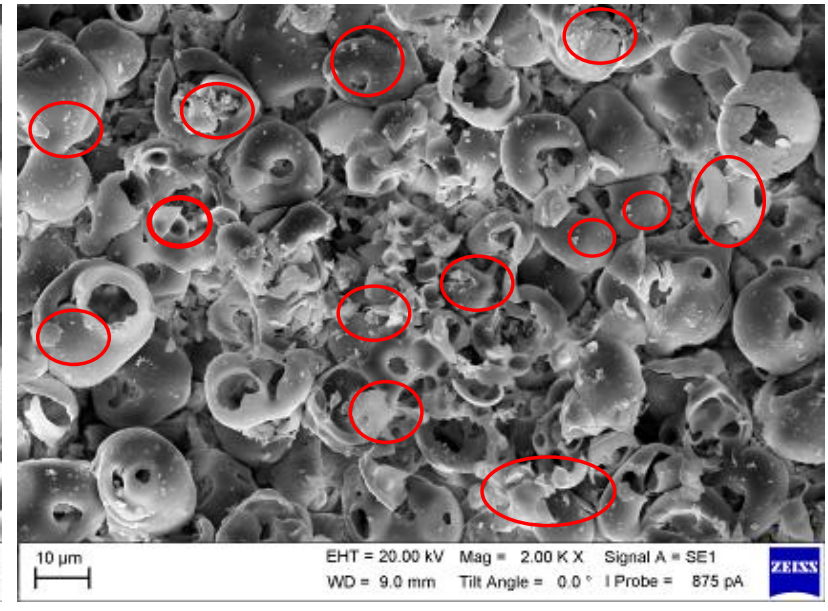

$\sigma$

Рис. 1. Типичные РЭМ-изображения немодифицированных КФ-покрытий $(a)$ и покрытий с наночастицами $\mathrm{Fe}-\mathrm{Cu}(б)$, сформированных методом МДО при напряжении процесса $250 \mathrm{~B}$

Исследование элементного состава покрытий методом энергодисперсионного микроанализа, показало, что в модифицированных КФ-покрытиях присутствуют следующие элементы: кальций $(6,7$ ат. \%); фосфор (22,3 ат. \%); кислород (55,0 ат. \%) и титан $(15,8$ ат. \%) (таблица). При этом в КФ-покрытиях, модифицированных нанокомпозитными частицами Fe$\mathrm{Cu}$, содержание кальция увеличивается от 4,5 до 6,7 ат. \%. Количество фосфора и титана после введения наночастиц увеличивается от 11,7 до 22,3 ат. \% и от 7,9 до 15,8 ат. \% соответственно. Концентрация кислорода в покрытии, напротив, уменьшается от 75,9 до 55,0 ат. \%.

Элементный состав немодифицированных КФ-покрытий и покрытий, модифицированных наночастицами $\mathrm{Fe}-\mathrm{Cu}$

\begin{tabular}{|l|c|c|c|c|c|c|}
\hline \multirow{2}{*}{ Образец покрытий } & \multicolumn{6}{|c|}{ Химические элементы, ат. \% } \\
\cline { 2 - 7 } & $\mathrm{O}$ & $\mathrm{Ca}$ & $\mathrm{P}$ & $\mathrm{Ti}$ & $\mathrm{Fe}$ & $\mathrm{Cu}$ \\
\hline КФ-покрытие & 75,9 & 4,5 & 11,7 & 7,9 & - & - \\
\hline $\begin{array}{l}\text { КФ-покрытие, модифи- } \\
\text { цированное наночасти- } \\
\text { цами } \mathrm{Fe-Cu}\end{array}$ & 55,0 & 6,7 & 22,3 & 15,8 & 0,1 & 0,1 \\
\hline
\end{tabular}

На рис. 2 представлены РЭМ-изображения немодифицированных КФ-покрытий, покрытий с наночастицами $\mathrm{Fe}-\mathrm{Cu}$ (рис. $2 a, \partial)$ и карты распределения элементов (Ca, $\mathrm{P}, \mathrm{O}, \mathrm{Ti}, \mathrm{Fe}$ и $\mathrm{Cu}$ ) по их поверхности (рис. $26-2, e-\kappa)$. Покрытия, сформированные при напряжении процесса МДО $250 \mathrm{~B}$, характеризуются однородным распределением фосфора и кислорода по их поверхности (рис. 2 a). Повышенная концентрация кальция сосредоточена в разрушенных сферах со скоплением частиц «чешуйчатой» формы размером меньше 1 мкм (рис. 2 б, частицы выделены эллипсами).

КФ-покрытия, модифицированные наночастицами $\mathrm{Fe}-\mathrm{Cu}$, также как и немодифицированные характеризуются однородным распределением фосфора и кислорода по поверхности (рис. 2 ж, з). Кроме того, кальций концентрируется в местах разрушенных сфер с более мелкими образованиями (рис. 2 e, выделены эллипсами). Модифицирующие элементы, в составе нанокомпозитных частиц $\mathrm{Fe}-\mathrm{Cu}$ распределены по покрытию однородно. 


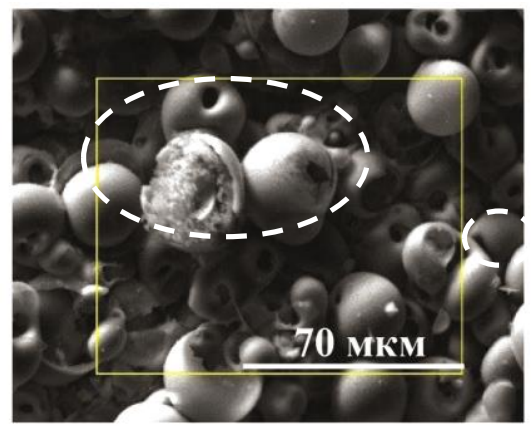

$a$

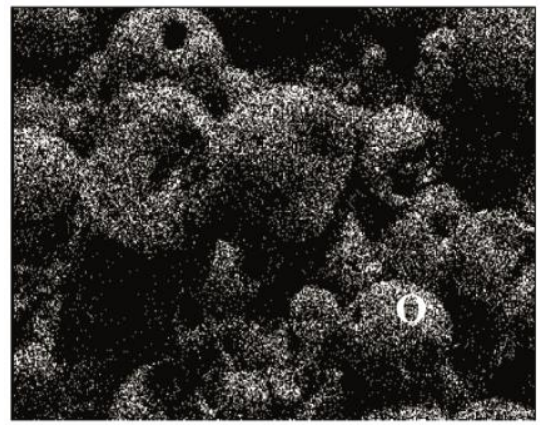

2

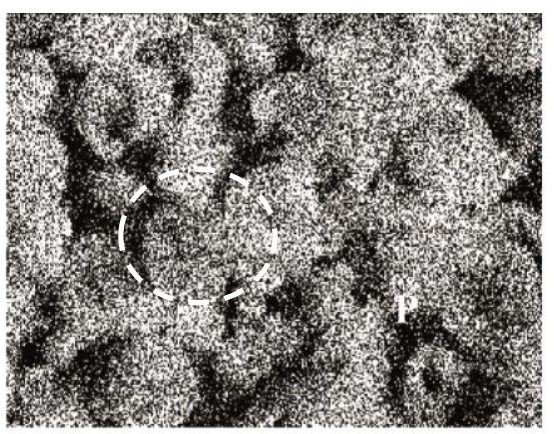



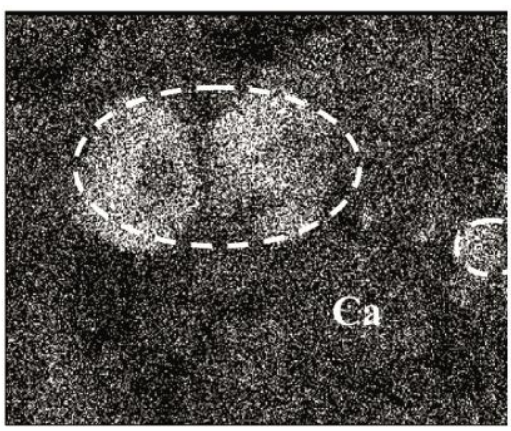

б

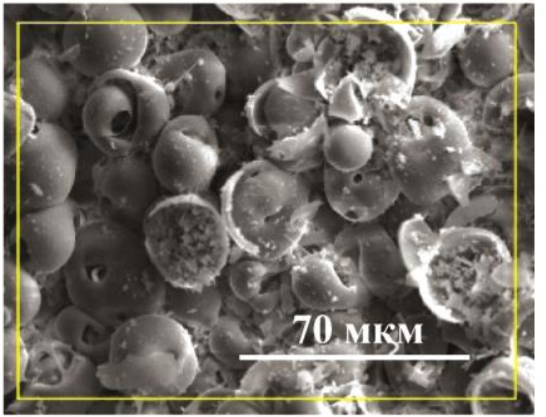

$\partial$

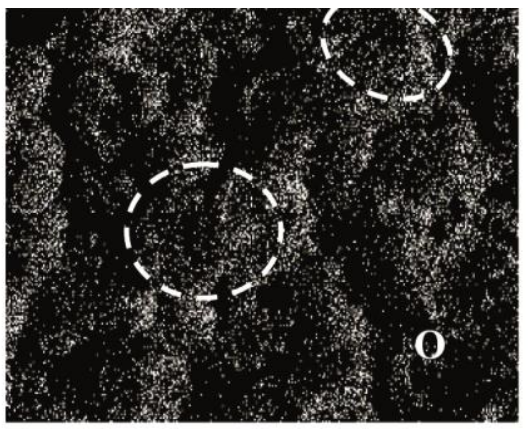

3

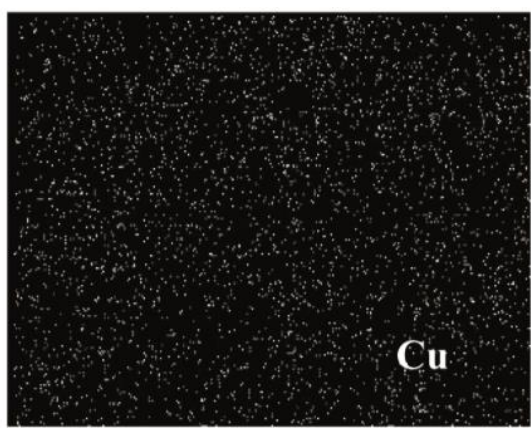

$\kappa$

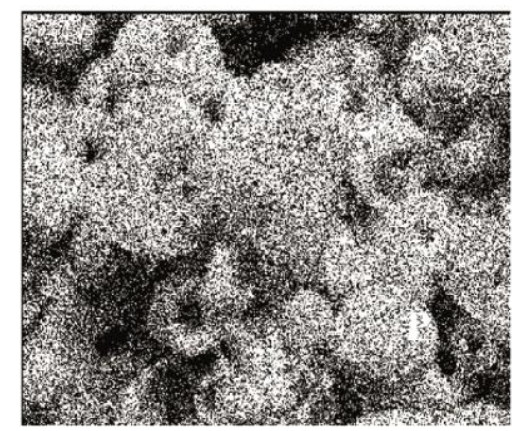

B

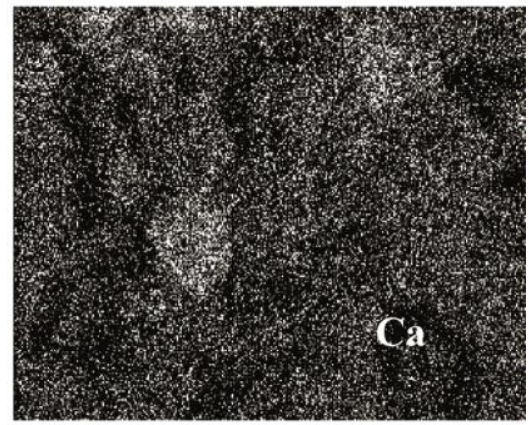

$e$

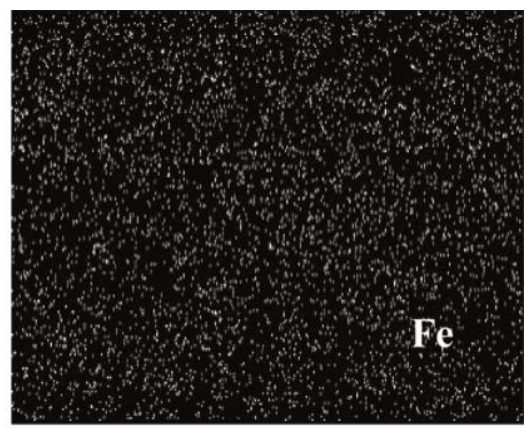

$u$

Рис. 2. Типичные РЭМ-изображения $(a, \partial)$ и карты распределения элементов покрытий, сформированных методом МДО при напряжении 250 В: $(a-2)-$ КФ-покрытия без наночастиц, $(\partial-\kappa)-$ КФ-покрытия с добавлением $\mathrm{Fe}-\mathrm{Cu}$ 


\section{4 Заключение}

В работе представлено исследование элементного состава и распределения элементов на поверхности кальций-фосфатных покрытий, сформированных при напряжении процесса МДО 250 В в электролите с добавлением наночастиц $\mathrm{Fe}-\mathrm{Cu}$. Кальций концентрируется в сферах покрытия с частицами «чешуйчатой» формы. Остальные элементы покрытия распределены однородно. Показано, что модификация покрытий наночастицами $\mathrm{Fe}-\mathrm{Cu}$ способствует повышению содержания кальция, фосфора и титана. При этом количество кислорода уменьшается от 75,9 до 55,0 ат. \%. Данный результат определяется участием ионов металлов $\mathrm{Fe}^{3+}$ и $\mathrm{Cu}^{2+}$ во время осаждения покрытия, способствующих интенсификации процессов МДО.

\section{Благодарность}

Авторы выражают благодарность д.х.н. М.В. Чайкиной, к.фр.-м.н. лаборатории интеркалляционных и механохимических реакций ИХТТМ СО РАН за подготовку стехиометрического гидроксиапатита и А.И. Толмачеву, сотруднику лаборатории наноструктурных биокомпозитов ИФПМ СО РАН, за помощьв в подготовке титановых пластин. 2021-0007.

Работа выполнена в рамках государственного задания ИФПМ СО РAH, проект FWRW-

\section{Литература}

1. Биокомпозиты на основе кальцийфосфатных покрытий, наноструктурных и ультрамелкозернистых биоинертных металлов, их биосовместимость и биодеградация / Ю. П. Шаркеев, С. Г. Псахье, Е. В. Легостаева, А. Г. Князева, А. Ю. Смолин, А. Ю. Ерошенко и др. - Томск : Издательский Дом Томского государственного университета, 2014. - 596 с.

2. Materials evolution of bone plates for internal fixation of bone fractures: A review / J. Li, L. Qin, K. Yang, Z. Ma, Y. Wang, L. Cheng, D. Zhao // Journal of Materials Science \& Technology. 2020. - Vol. 36. - P. 190-208. - DOI: 10.1016/j.jmst.2019.07.024.

3. Composite polymer-bioceramic scaffolds with drug delivery capability for bone tissue engineering / V. Mourico, J. P. Cattalini, J. A. Roether, P. Dubey, I. Roy, A. R. Boccaccini // Expert Opinion on Drug Delivery. - 2013. - Vol. 10 (10). - P. 1353-1365. - DOI: 10.1517/17425247.2013.808183.

4. Structural, morphological and adhesive properties of calcium phosphate coatings formed on magnesium alloy by micro-arc oxidation method in electrolyte containing dispersed particles / M. B. Sedelnikova, A. V. Ugodchikova, P. V. Uvarkin, V. V. Chebodaeva, T. V. Tolkacheva, D. Schmidt, Yu. P. Sharkeev // Russian Physics Journal. - 2021. - DOI: 10.1007/s11182-021-02398-Z.

5. Surface modification of $\mathrm{Mg} 0.8 \mathrm{Ca}$ alloy via wollastonite micro-arc coatings: Significant improvement in corrosion resistance / M. B. Sedelnikova, A. V. Ugodchikova, T. V. Tolkacheva, V. V. Chebodaeva, I. A. Cluklhov, M. A. Khimich, O. V. Bakina, M. I. Lerner, V. S. Egorkin, J. Schmidt, Y. P. Sharkeev // Metals. - 2021. - Vol. 11 (5). - 754. - DOI: 10.3390/met11050754.

6. Influence of electrolyte composition on microstructure, adhesion and bioactivity of microarc oxidation coatings produced on biomedical Ti6Al7Nb alloy / J. Karbowniczek, F. Muhaffel, G. Cempura, H. Cimenoglu, A. Czyrska-Filemonowicz // Surface and Coatings Technology. 2017. - Vol. 321. - P. 97-107. - DOI: 10.1016/j.surfcoat.2017.04.031.

7. Introduction to plasma electrolytic oxidation - an overview of the process and applications / F. Simchen, M. Sieber, A. Kopp, T. Lampke // Coatings. - 2020. - Vol. 628 (10). DOI: $10.3390 /$ coatings10070628.

8. Dorozhkin S. V. Calcium orthophosphate deposits: Preparation, properties and biomedical applications // Materials Science and Engineering C. - 2015. - Vol. 55. - P. 272-326. DOI: 10.1016/j.msec.2015.05.033. 
9. Influence of current density and electrolyte concentration on DC PEO titania coatings / R. H. U. Khan, A. L. Yerokhin, X. Li, H. Dong, A. Matthews // Surface Engineering. - 2014. Vol. 30 (2). - P. 102-108. - DOI: 10.1179/1743294413Y.0000000225.

10. Effect of Boehmite Nanoparticles on the Structural, Corrosion, and Diffusion Properties of Microarc Biocoatings / V. V. Chebodaeva, N. N. Nazarenko, M. B. Sedelnikova, S. V. Gnedenkov, V. S. Egorkin, S. L. Sinebryukhov, and Yu. P. Sharkeev // Inorganic Materials: Applied Research. - 2021. - Vol. 12, No. 3. - P. 691-699. - DOI: 10.1134/S2075113321030072.

11. Influence of Metal Based Nanoparticles on Properties of Micro-arc Calcium Phosphate Coatings / V. Chebodaeva, M. Sedelnikova, V. Bazhanova, M. Lerner, A. Pervikov, Yu. Sharkeev // AIP Conference proceedings - 2019. - Vol. 2167. - P. 020049-1-020049-4. - DOI: 10.1063/1.5131916.

12. Fabrication of $\mathrm{Fe}-\mathrm{Cu}$ composites from electroexplosive bimetallic nanoparticles by spark plasma sintering / A. S. Lozhkomoev, A. V. Pervikov, A. V. Chumaevsky, E. S. Dvilis, V. D. Paygin, O. L. Khasanov, M. I. Lerner // Vacuum. - 2019. - Vol. 170. - 108980. DOI: $10.1016 /$ j.vacuum.2019.108980.

13. Control of smooth muscle cell proliferation by ferrous iron / P. P. Mueller, T. May, A. Perz, H. Hauser, M. Peuster // Biomaterials. - 2006. - Vol. 27. - P. 2193-2200. DOI: $10.1016 /$ j.biomaterials.2005.10.042.

14. Fabrication of $\mathrm{Fe}-\mathrm{Cu}$ composites from electroexplosive bimetallic nanoparticles by spark plasma sintering / A. S. Lozhkomoev, A. V. Pervikov, A. V. Chumaevsky, E. S. Dvilis, V. D. Paygin, O. L. Khasanov, M. I. Lerner // Vacuum. - 2019. - Vol. 170. - P. 108980. DOI: 10.1016/j.vacuum.2019.108980. 